\title{
REFORMA TRABALHISTA: precarização do trabalho e os desafios para o sindicalismo
}

\author{
Andréia Galvão* (https://orcid.org/0000-0002-7835-3071) \\ Bárbara Castro * * (https://orcid.org/0000-0002-9526-8776) \\ José Dari Krein *** (https://orcid.org/0000-0002-4277-2290) \\ Marilane Oliveira Teixeira **** ${ }_{(\text {https://orcid.org/0000-0003-0246-9147) }}$
}

\begin{abstract}
O artigo se propõe a identificar os impactos iniciais da reforma trabalhista sobre o sindicalismo em um contexto desfavorável aos trabalhadores e à ação coletiva, dado o crescimento da precariedade e da informalidade no mercado de trabalho. A análise trata da reconfiguração das classes trabalhadoras e da fragmentação sindical, bem como dos impactos da reforma sobre as estratégias e ações sindicais e sobre as negociações coletivas. A metodologia combinou pesquisas quantitativas sobre mercado de trabalho com análise documental (instrumentos normativos, matérias de imprensa comercial e sindical) e observação participante. Os resultados mostram que os sindicatos buscam se adaptar ao novo contexto, com pequenas inovações substantivas na ação e organização, e que as negociações têm sido tanto espaço de resistência quanto de legitimação do conteúdo da reforma.
\end{abstract}

Palavras-CHAve: Sindicalismo. Reforma trabalhista. Precariedade. Negociações coletivas.

\section{INTRODUÇÃO}

Após um período favorável, entre os anos 2004-2014, o movimento sindical brasileiro enfrenta novamente dificuldades de atuação. A dupla crise econômica e política, instalada desde 2015 no país, vem deteriorando as condições de trabalho e de vida das classes populares (Galvão; Marcelino, 2018). As políticas de austeridade implementadas pelos governos Temer e Bolsonaro e a ofensiva sobre os direitos sociais e trabalhistas alteraram as

\footnotetext{
* Universidade Estadual de Campinas (Unicamp). Departamento de Ciência Política.

Rua Cora Coralina, 100 - Cidade Universitária Zeferino Vaz, Barão Geraldo. Cep: 13083-896. Campinas - São Paulo-Brasil. agalvao@unicamp.br

** Universidade Estadual de Campinas (Unicamp). Departamento de Sociologia.

Rua Cora Coralina, 100 - Cidade Universitária Zeferino Vaz, Barão Geraldo. Cep: 13083-896. Campinas - São Paulo Brasil.bgcastro@unicamp.br

*** Universidade Estadual de Campinas (Unicamp). Instituto de Economia. Centro de Estudos Sindicais e Economia do Trabalho (CESIT).

Rua Pitagoras, 353, Cidade Universitária Zeferino Vaz. Cep: 13083-857 Campinas - São Paulo - Brasil. darik@ unicamp.br

**** Universidade Estadual de Campinas (Unicamp). Instituto de Economia. Centro de Estudos Sindicais e Economia do Trabalho (CESIT). Rua Pitagoras, 353, Cidade Universitária Zeferino Vaz. Cep: 13083-857 Campinas - São Paulo-Brasil.mari@uol.com.br
}

tendências de geração de emprego e formalização que vinham sendo observadas até então e fragilizaram os sindicatos. A reforma trabalhista aprovada em 2017 intensificou esse processo, pois a ampliação de formas precárias de contratação estimula a fragmentação das bases de representação sindical. A reforma também interfere na capacidade de negociação dos sindicatos, ao possibilitar a negociação individual de aspectos das relações de trabalho e a rescisão contratual sem intermediação sindical. Sua dimensão antissindical se revela pela criação de comissões destinadas a representar os trabalhadores no local de trabalho em concorrência com os sindicatos. Por fim, a reforma impacta suas finanças, ao condicionar a cobrança do imposto sindical à anuência prévia do trabalhador (Galvão et al., 2017).

Análises precedentes mostram que as mudanças implementadas a partir da lei 13.467/17 aprofundaram a precarização do trabalho, sobretudo entre as mulheres (Krein et al., 2018; Krein; Véras, 2019). Diante das dificuldades historicamente apresentadas pelo movimento sindical brasileiro para representar os trabalhadores precários (Galvão; Krein, 2019) e 
as mulheres (Araújo; Ferreira, 2000), cabe indagar de que maneira a reforma trabalhista repercute sobre as relações de trabalho e a ação dos sindicatos, com foco na questão da precarização do trabalho. Esse é o objetivo do presente artigo.

Na primeira seção do artigo, buscamos caracterizar o contexto mais geral em que a ação sindical se desenvolve. Na segunda, analisamos alguns dados referentes ao mercado de trabalho e à sindicalização, para dimensionar as alterações decorrentes da crise econômica e política. $\mathrm{Na}$ terceira, identificamos a posição do movimento sindical sobre a reforma e suas estratégias de enfrentamento. Na quarta, examinamos as negociações coletivas. Os dados aqui apresentados têm origem em pesquisas quantitativas sobre mercado de trabalho entre 2012-2018 (PNADC) ${ }^{1}$, em análise documental (instrumentos normativos, matérias de imprensa comercial e sindical) e em observação participante.

\section{UM CONTEXTO DESFAVORÁVEL PARA A AÇÃO SINDICAL}

O período de 2004-2014 se caracterizou pela melhoria dos indicadores macroeconômicos e do mercado de trabalho, com redução do desemprego e da informalidade, reajustes saF lariais superiores à inflação e valorização do N. salário mínimo. No plano negocial, houve uma crescente participação de representantes sindicais nas instituições estatais, o que colocou novas questões para o debate sobre a capacidade de ação sindical. Partindo de referenciais e indicadores distintos, vários autores convergiram no reconhecimento do crescimento de um maior ativismo na negociação coletiva e na conflituosidade nas relações de trabalho.

A partir dos indicadores de greve, Boito Junior e Marcelino (2010) consideraram ser possível identificar, desde 2004, uma recuperação da atividade sindical no Brasil. Os auto-

${ }^{1}$ Com a mudança metodológica da PNAD adotada desde 2012 pelo IBGE, a série histórica para os dados de associação foram interrompidas, não sendo mais possível fazer comparações com o período anterior. res avaliam que os bons resultados do mercado de trabalho no período viabilizaram o apoio da grande maioria do movimento sindical aos governos petistas e inauguraram uma "nova fase do sindicalismo brasileiro", que combinava uma forte e vitoriosa atividade no plano da luta reivindicativa e uma orientação política moderada na cúpula do movimento sindical (Boito; Galvão; Marcelino, 2015).

Se o aumento de greves e do número de sindicalizados, a melhoria nas negociações coletivas e a ampliação dos canais de interlocução com o governo podem ser identificados como sinais de revitalização sindical, outros indicadores apontam para "a perda de força e importância do sindicalismo na sociedade, com o crescente descrédito da instituição sindical" (Krein; Dias, 2017, p. 15). Os sindicatos assumiram uma atitude passiva e subordinada às iniciativas do governo (Araújo; Véras de Oliveira , 2010), tornando-se incapazes de vocalizar um projeto de desenvolvimento fundado na distribuição de renda e na valorização do trabalho (Colombi, 2018).

O crescimento de greves evidencia a eficácia do sindicalismo em mobilizar os trabalhadores em nome de demandas econômico-corporativas, mas não se deve desconsiderar que muitas dessas greves foram convocadas à revelia das direções sindicais (Campos, 2016; Linhares, 2015; Mattos, 2014; Véras de Oliveira, 2014). Ao mesmo tempo, o ambiente economicamente favorável e a identificação política entre a maior parcela do movimento sindical e os governos petistas reduziram sua capacidade de mobilizar os trabalhadores em torno de mudanças na legislação e nas políticas públicas, como a baixa adesão às marchas da classe trabalhadora e às jornadas de lutas e paralisações convocadas pelas centrais após as manifestações de junho de 2013 revela (Galvão; Marcelino, 2018). A confiança nos sindicatos também se reduziu. Entre 2009 e 2013, o índice de confiança medido pelo Ibope Inteligência recuou de 46 para 37 pontos, chegando a 35 pontos em 2018. ${ }^{2}$

${ }^{2}$ Cf. http://www.ibopeinteligencia.com/noticias-e-pesqui- 
A mudança de contexto é uma variável importante para explicar essa perda de confiança. O descontentamento dos trabalhadores com um sindicalismo majoritariamente identificado com o governo pode ter se ampliado no momento em que o projeto político petista entra em crise (Cardoso, 2015). A desestruturação do mercado de trabalho a partir de 2015, com a reversão dos indicadores de desocupação e informalização, pode ter incitado o afastamento daqueles segmentos que, ao perderem emprego e ao viverem entre a subocupação e o desalento, deixaram de ser representados pelos sindicatos. $\mathrm{O}$ apoio do sindicalismo hegemônico ao governo Rousseff e sua posição contrária ao impeachment da presidenta pode ter contribuído para o afastamento daqueles que identificam o PT à corrupção. Por outro lado, o movimento sindical realizou a greve geral de 28 de abril de 2017, que contou com a adesão de 35 milhões de trabalhadores e que, a despeito de ser considerada a maior greve geral da história, não foi capaz de barrar a reforma trabalhista. Assim, diante da persistência da crise econômica e política, bem como da hostilidade dirigida à esquerda, que culminou na eleição de Bolsonaro em 2018, o movimento sindical sofreu um novo recuo. O balanço das greves realizado pelo Dieese (2019) registra 1453 greves em 2018, número inferior ao de 2017, mas superior aos patamares anteriores a 2013. Porém os dados indicam uma pauta predominantemente defensiva em $81,8 \%$ das mobilizações, sugerindo o prenúncio de um novo ciclo defensivo, conforme apontou Marcelino (2017). ${ }^{3}$

A trajetória do sindicalismo também foi afetada por um contexto internacional desfavorável ao trabalho e à ação coletiva, causado tanto pela reestruturação das empresas e pelas mudanças nos processos produtivos quanto pela hegemonia neoliberal e as suas políticas

sas/confianca-do-brasileiro-nas-instituicoes-e-a-mais-baixa-desde-2009/

${ }^{3}$ Os ciclos econômicos recessivos levam à redução do número de pessoas associadas, mas precisam ser cotejados com outros aspectos, como as ações dos sindicatos para ampliar seu quadro de associados, o contexto político e os resultados das negociações coletivas (cf. Alcantara e Silva, 2017). de desconstrução de direitos. Ou seja, as dificuldades internas também estão relacionadas às transformações mais profundas nos contornos do capitalismo contemporâneo.

\section{A RECONFIGURAÇÃO DA CLAS- SE TRABALHADORA E SEUS IM- PACTOS NA SINDICALIZAÇÃO}

As transformações na dinâmica econômica e social indicam uma profunda reconfiguração da classe trabalhadora, com a perda de importância relativa dos setores em que o sindicalismo historicamente mostrou maior capacidade de organização e ação coletiva e crescimento de ocupações mais precárias. Embora a precariedade não seja exatamente uma novidade no mercado de trabalho brasileiro, dada a histórica informalidade e a ausência de proteção legal que o caracterizam, a proliferação de contratos atípicos amplia a vulnerabilidade dos trabalhadores e dificulta a ação sindical, já que esses trabalhadores são dificilmente representados pelos sindicatos.

Os dados sobre sindicalização mostram que os setores que podemos classificar como precários, a exemplo do setor informal da economia (assalariados sem carteira, autônomos sem contribuição para a previdência) e dos setores formais tipicamente terceirizáveis (operadores de telemarketing, informática, asseio e conservação) apresentam uma taxa de sindicalização mais baixa que a média nacional, o que nos leva a indagar sobre as possibilidades de ação coletiva nos setores precarizados (Galvão; Krein, 2019). No período entre 2003 e 2013, verificou-se uma redução na densidade sindical, a despeito da criação de empregos, o que se deve, principalmente, às características dos empregos gerados, em grande parte em setores com fraca tradição sindical, como a construção civil e o comércio (Alcantara e Silva; Krein, 2015, p. 9).

Entre os últimos trimestres de 2014 e 2018, houve um crescimento de $89 \%$ da desocupação e um crescimento tímido da ocupa- 
ção $(0,1 \%)$, o que confirma a crise do mercado de trabalho. Entre os ocupados, os informais ganharam espaço, com um crescimento de $8,1 \%$ e queda de $-7,9 \%$ do trabalho formal. ${ }^{4}$ De $46,3 \%$ da população ocupada, os informais passaram a $50,3 \%$ no período. ${ }^{5}$

Há uma dinâmica de gênero articulada ao processo de deterioração do mercado de trabalho. A divisão sexual do trabalho se expressa tanto nas características dos postos que estão sendo criados quanto na forma de inserção de ambos os sexos. Diante da crise, as mulheres são forçadas a ingressar em trabalhos mais flexíveis como forma de compatibilizar as responsabilidades domésticas e familiares que lhes são atribuídas. A ausência de políticas, decorrente da redução do orçamento público, impõe às mulheres, especialmente as negras, a opção de se inserir em trabalhos precários, informais, realizados, na maioria das vezes, no âmbito dos domicílios.

As atividades que tiveram maior queda de ocupados no período de 2014 a 2018 têm uma maior presença de homens: agricultura, pecuária, produção florestal, pesca e aquicultura (-10,2\%), administração pública, defesa e seguridade social o̊ $(-6,5 \%)$, indústria geral $(-12,1 \%)$ กิ e construção $(-12,3 \%) .{ }^{6}$ As ocu$\dot{8}$ $\stackrel{0}{\perp}$ pações cresceram nas ativida-

$\sum 4$ Estamos considerando trabalhadores j formais os empregados com carteira, tra-

$\stackrel{0}{\sim}$ balhadores domésticos com carteira, mi-

ผ่ litares e servidores públicos e informais

ㄱ os empregados sem carteira, trabalhadores domésticos

$\dot{2}$ sem carteira, conta-própria e trabalhadores familiares au0 xiliares.

¿ ${ }^{5} \mathrm{O}$ índice de desocupação foi ligeiramente pior para as i mulheres: cresceu 90, 2\% entre elas, alcançando 6,3 mi-

๓ lhões de mulheres, e 87,8\% entre eles, alcançando 5,8 mi-

$>$ lhões de homens. O crescimento da ocupação foi maior

ธิ entre elas (2\%), mais especialmente entre as mulheres ne-

gras (7\%). A maior taxa de ocupação se desdobrou em um

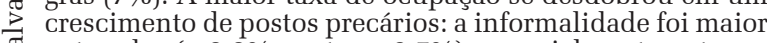

๙ entre elas $(+9,9 \%$ contra $+6,7 \%)$, especialmente entre as

mulheres negras $(+13,7 \%)$, e o decréscimo da formalidade maior para eles $(-10,1 \%$ contra $+0,7 \%)$.

○ $\quad{ }^{6}$ Vale destacar que a queda é ainda maior se olharmos para o período que abrange 2012 a 2018: -17\% na agricultura, pecuária, produção florestal, pesca e aquicultura e -13,4\% $\circlearrowleft$ na administração pública, defesa e seguridade social.

Tabela 1 des em que as mulheres são tradicionalmente maioria e nos quais elas seguem ocupando a maioria dos postos de trabalho, embora, recentemente, venha aumentando a participação dos homens. Além disso, como veremos, esses setores que se caracterizavam pela formalidade dos vínculos têm ampliado a informalidade. As atividades de alojamento e alimentação cresceram 25,2\% no total (32\% entre os homens), educação, saúde humana e serviços sociais, $13,3 \%$ no total ( $15 \%$ entre os homens); e outros serviços, $17,2 \%$ no total (23\% entre os homens). Destaque-se também o crescimento excepcional da ocupação nas atividades mal definidas: ele foi da ordem de 92,1\% entre 2014 e 2018 e de 187,9\% entre 2012 e 2018. ${ }^{7}$ Há um movimento presente na crise, portanto, de concentração de vagas de trabalho nos setores mais feminizados e que, à exceção da educação e saúde, em âmbito público, contam com baixa organização e mobilização sindical.

\begin{tabular}{l|c|c|c}
\hline \multicolumn{4}{c}{ Evolução da ocupação por posição e atividade econômica entre 2014 e 2018, por sexo (\%) } \\
\hline & Mulheres & Homens & Total \\
\hline Ocupação & 2,3 & $-1,5$ & 0,1 \\
\hline Desocupação & 90,2 & 87,8 & 89,0 \\
\hline Formais & $-5,2$ & $-10,1$ & $-7,9$ \\
\hline Informais & 9,9 & 6,7 & 8,1 \\
\hline Agricultura, pecuária, prod. florestal & $-16,9$ & $-8,4$ & $-10,2$ \\
\hline Administração pública, defesa e seguridade social & $-11,1$ & $-3,0$ & $-6,5$ \\
\hline Indústria geral & $-8,5$ & $-13,9$ & $-12,1$ \\
\hline Construção & 0,3 & $-12,6$ & $-12,3$ \\
\hline Alojamento e alimentação & 19,8 & 32,7 & 25,2 \\
\hline Educação, saúde humana e serviços sociais & 12,6 & 15,5 & 13,3 \\
\hline Outros serviços & 13,1 & 23,1 & 17,2 \\
\hline Atividades mal definidas & 72,8 & 102,2 & 92,1 \\
\hline
\end{tabular}

Para entender esse movimento recente de crescimento de postos de trabalho tipicamente feminizados, vale destacar que as atividades que mais ocupavam os trabalhadores no final de 2018 mudaram em relação ao $1^{\circ}$ trimestre de 2012. Naquele ano, entre as atividades mais masculinizadas, comércio, reparação ${ }^{7}$ Essa é a única atividade que seguiu crescendo com dois
dígitos entre 2017 e 2018: + $34,7 \%$. Entre 2014 e 2018,
cresceu especialmente entre mulheres negras $(+195,6 \%)$,
homens negros $(+177,4 \%)$ e mulheres brancas $(+132,6 \%)$. 
de veículos automotores e motocicletas concentravam 18,7\% dos ocupados (equivalente a 16,4 milhões de ocupados), seguidas pela indústria (14,7\%), agricultura (11,7\%) e informação, comunicação e atividades financeiras, imobiliárias, profissionais e administrativas $(10,7 \%)$. Ao final de 2018, as atividades de comércio, reparação de veículos automotores e motocicletas seguiam liderando a concentração de ocupados (19,3\%), seguidas pelas da indústria $(12,7 \%)$. Mas a agricultura $(9,1 \%)$ perdeu espaço para as atividades em que predominam mulheres: educação, saúde humana e serviços sociais concentravam $12,1 \%$ dos trabalhadores, e informação, comunicação e atividades financeiras, imobiliárias, profissionais e administrativas, $11,1 \%$.

Ainda que incipiente e recente, essa mudança ajuda a pensar a dinâmica da precariedade articulada a trabalhos com maior presença de mulheres. As atividades de educação, saúde humana e serviços sociais só perdem para as de administração pública, defesa e seguridade social em termos de maior índice de contratos formais (respectivamente 73,0\% e 79,2\% no último semestre de 2018), muito embora tenha havido um crescimento de informais de $2 \mathrm{pp}$. entre 2014 e 2018. Mesma tendência aparece para as atividades financeiras, imobiliárias, profissionais e administrativas, $3^{\circ}$ maior índice de formalidade (66,5\%), com crescimento de $+5,5 \mathrm{pp}$ de informalidade no período.

A tendência de crescimento da informalidade em setores tipicamente formais e femininos nos dá elementos para pensar na degradação das condições de trabalho e nos desafios colocados para a ação sindical no contexto de crise e de vigência da reforma trabalhista. Pois não são apenas os setores tipicamente vulneráveis que são afetados por ela: os setores tipicamente formais e sindicalizados são igualmente atingidos, uma vez que os empregadores passam a ter diante de si um amplo cardápio de formas legalizadas de contratação que rebaixam direitos.

Tomemos o exemplo do MEI, modalidade de contratação que precede a reforma de 2017.
Implementado em 2009 com o objetivo de ampliar o acesso dos informais a direitos sociais, especialmente o previdenciário, teve uma consequência adversa - o crescimento de relações de emprego disfarçadas (fraudes) e da individualização do acesso a direitos, ${ }^{8}$ o que pode contribuir para o enfraquecimento dos sindicatos.

As mudanças nas formas de contratação impactam na sindicalização. Do total das pessoas ocupadas em 2012, 16,2\% se declararam associadas a sindicatos. Em 2017, esse percentual caiu para $14,4 \%$, o que perfaz uma queda de 9,3\% entre 2012 e 2017. Mas a evolução da sindicalização não ocorreu de maneira uniforme por sexo e cor ou raça, sendo possível identificar três situações: na primeira, a queda na taxa de sindicalização ocorreu de forma mais acentuada do que a queda nos níveis de emprego; entre os homens brancos o emprego recuou $(-5,2 \%)$ e a sindicalização $(-16,2 \%)$; entre as mulheres brancas, caíram o emprego $(-2,6 \%)$ e a sindicalização $(-9,8 \%)$. Na segunda situação, o emprego cresceu com queda na taxa de sindicalização; entre os homens negros, o emprego cresceu $(+4,3 \%)$, e a sindicalização caiu (-11,5\%). Na terceira situação, que se refere às mulheres negras, emprego e sindicalização evoluíram positivamente: 11,7\% e 6,1, respectivamente.

A taxa de sindicalização caiu tanto para os trabalhadores formais quanto para os informais, excetuando-se o trabalho doméstico com e sem carteira, mesmo assim não de forma uniforme e contínua. A associação entre as trabalhadoras domésticas com carteira cresceu $30,6 \%$ no período, consequência da regulamentação da profissão por Lei Complementar aprovada em junho de 2015. Mas a sindicalização caiu de forma expressiva entre os empregados do setor público $(-16,6 \%)$ e as pessoas empregadas com carteira de trabalho $(-11,5 \%)$.

Quando se analisa por grupamentos de atividade, a queda foi mais acentuada entre as pessoas que trabalham em agricultura $(-23,4 \%)$,

${ }^{8}$ Tal como apontado por Castro (2016) no que se refere ao processo de pejotização verificado no mesmo período. 
indústria (-25,3\%), administração pública $(-17,6 \%)$ e em atividades mal definidas $(-29,5 \%)$. Em contrapartida, a taxa se ampliou para o setor de alojamento e alimentação ( $+24,2 \%)$, educação, saúde humana e serviços sociais $(+17,3 \%)$, outros serviços $(+21,1 \%)$ e serviços domésticos $(+18,1 \%)$. Já os piores resultados, proporcionalmente, podem ser atribuídos à indústria e à construção civil, setores em que a taxa de sindicalização caiu de forma mais intensa que o emprego: $-7,9 \%$ de emprego na indústria e -25,3\% de sindicalizados; -6,4\% na construção e -27,2\% de sindicalizados (Tabela 2).

Tabela 2 - Taxa de sindicalização por grupamentos de atividade - Brasil (\%)

\begin{tabular}{l|c|c}
\hline \multirow{2}{*}{\multicolumn{1}{c|}{ Atividade econômica }} & \multicolumn{2}{c}{ Variação entre 2012-2017 } \\
\cline { 2 - 3 } & Emprego & Sindicalização \\
\hline Agricultura, pecuária, prod. Florestal, pesca & $-15,9$ & $-23,4$ \\
\hline Indústria geral & $-7,9$ & $-25,3$ \\
\hline Construção & $-6,4$ & $-27,2$ \\
\hline Comércio, reparação de veículos & 3,8 & $-1,0$ \\
\hline Transporte, armazenagem e correio & 8,1 & $-8,8$ \\
\hline Alojamento e alimentação & 39,3 & 24,2 \\
\hline Informação, comunicação e atividades financeiras & 4,6 & $-5,5$ \\
\hline Administração pública, defesa e seguridade social & $-12,1$ & $-17,6$ \\
\hline Educação, saúde humana e serviços sociais & 23,4 & 17,3 \\
\hline Outros serviços & 18,2 & 21,1 \\
\hline Serviços domésticos & 0,7 & 18,1 \\
\hline Atividades mal definidas & $-10,1$ & $-29,5$ \\
\hline
\end{tabular}

Fonte: Microdados PNADC/IBGE - Elaboração própria

Em síntese, a sindicalização acompaem que se destaca a progressiva queda de atividades mais tradicionais do ponto de vista sindical. Em contrapartida, a sindicalização cresceu no setor de serviços que, com exceção da saúde e educação, apresenta histórica fragilidade sindical. tramitação. mas há outros fatores a interferir nesse processo. As principais centrais não conseguiram construir um consenso sobre o significado da reforma, o que contribuiu para explicar certo esvaziamento das ações coletivas durante sua

As estratégias oscilaram entre a rejeição total da proposta, com mobilização social, e (ou) a interlocução com o Congresso e com o Governo Temer, buscando preservar as condições de sobrevivência dos sindicatos. A Força Sindical, com a anuência de outras centrais, apostou na estratégia da negociação, na esperança de que a instituição sindical seria preservada (Colombi; Lemos; Krein, 2018). Uma das consequências dessa dubiedade foi a escassez de materiais de massa críticos à reforma.

Apesar de um calendário comum de mobilização e a despeito da expressiva greve geral de 2017, já citada, as ações unificadas entre as centrais foram perdendo fôlego (Galvão; Marcelino, 2018). ${ }^{10}$ As atividades programadas se esvaziaram no período de votação (julho de 2017) e de implementação da reforma (novembro 2017) e apresentaram dificuldades de coordenação. Essa desarticulação tem relação, entre outros fatores, com os posicionamentos distintos entre elas. A cerimônia de lançamento da proposta de reforma pelo Governo Temer contou com a presença de três centrais sindicais (Força Sindical, UGT e CSB). Na oportunidade, o secretário-geral da Força Sindical, o Juruna, defendeu que o projeto - posteriormente ampliado no Congresso - poderia fortalecer o papel dos sindicatos. ${ }^{11}$ Para ele, "com ajustes 'a reforma

${ }^{10}$ Convém assinalar que o amplo projeto de desmonte de direitos desenhado pelo governo Bolsonaro pode representar uma mudança de rumo a esse respeito. Vide o ineditis-

A deterioração do mercado de trabalho mo da celebração conjunta do $1^{\circ}$ de maio de 2019 , o vigor demonstrado pela manifestação em defesa da educação e contra a reforma da previdência em 15 de maio, e o anúncio de uma greve geral em 14 de junho.

${ }^{11}$ Segundo ele, o projeto valorizava a negociação coletiva e a presença sindical nos debates e sugeria um clima de não judicialização dos conflitos. Com a maior flexibilização, o 
ganha equilíbrio e avança na direção da modernização das relações de trabalho e da estrutura sindical. É o que defendemos”". Já a CUT adotou um discurso de contraposição global à reforma, por entender que todas as alterações beneficiariam apenas os empresários. Para seu presidente, Vagner Freitas, não se tratava de "uma "modernização" das relações laborais, mas sim [de] uma legitimação da precarização do trabalho no país [... que também] visa a atacar o sindicalismo, por meio do esvaziamento das prerrogativas sindicais." (Colombi; Lemos; Krein, 2018, p. 185-186, 195).

Essas diferenças fizeram com que a Agenda Prioritária da Classe Trabalhadora para as eleições de 2018, aprovada por sete centrais (CUT, FS, CTB, UBT, Nova Central, CSB e Intersindical), apresentasse apenas uma reivindicação genérica: a alteração de aspectos negativos da reforma. ${ }^{12}$ Os posicionamentos distintos, porém, não inviabilizam uma crítica comum das centrais, que consideraram a reforma um "retrocesso da proteção social ao trabalho aos primórdios do processo de industrialização no país.” (Galvão; Teixeira, 2018, p. 169). As críticas se estendem à sustentação financeira das entidades, à perda de prerrogativas sindicais com a criação da comissão de representação dos trabalhadores nas empresas e a descentralização da negociação para o âmbito da empresa e para o trabalhador individual, e ao caráter facultativo da realização das homologações nos sindicatos.

Essa análise é corroborada por pesquisa realizada pela Rede de Estudos e Monitoramento Interdisciplinar da Reforma Trabalhis-

trabalhador terá voz para dizer como quer dividir as férias ou a jornada de trabalho, por exemplo. "Não é o patrão que vai impor, vai ser feito em negociação em que o trabalhador vai propor, o sindicato vai representar e isso será feito”. Cf. Agência Brasil, 22/12/2016. O governo propõe que o acordo prevaleça sobre a lei. In: http://agenciabrasil. ebc.com.br/economia/noticia/2016-12/acordo-entre-trabalhadores-e-empresas-vai-prevalecer-sobre-legislacao.

${ }^{12}$ Cf. o documento: "Revogar todos os aspectos negativos apontados pelos trabalhadores da Lei 13.467 (Reforma Trabalhista) e da Lei 13.429 (Terceirização), que precarizam os contratos e condições de trabalho, na perspectiva da construção de um novo estatuto, com valorizaçã̃o do trabalho". ta (REMIR) junto a dirigentes sindicais, ${ }^{13}$ que registrou uma tendência majoritária (95\%) de respondentes contrários e somente 2,5\% favoráveis à reforma, sendo que 92\% defendiam sua completa revogação. No entanto, 10\% dos respondentes identificaram aspectos positivos, entre os quais se destacam: (1) a prevalência do negociado sobre o legislado; e (2) o fim da obrigatoriedade da contribuição sindical, por se entender que essas medidas dinamizariam a atuação sindical.

As estratégias que começam a predominar tendem a ser pragmáticas, pois buscam ajustar o movimento sindical aos novos parâmetros da reforma, tanto do ponto de vista da organização e da estrutura sindical, quanto da negociação coletiva. A seguir, analisamos como a nova realidade começou a enfrentada pelo movimento sindical.

\section{A prevalência do negociado sobre o legislado}

A tese de que as negociações coletivas deveriam assumir um papel mais destacado na determinação das condições de contratação, uso e remuneração do trabalho não é nova, nem é exclusividade do discurso patronal e governamental. Ela foi defendida pelo novo sindicalismo, tendo como referência um padrão de regulação do trabalho construído sob o fordismo. Nos anos 1990, muitas entidades de referência da CUT e da Força Sindical negociaram formas de contratação, jornada e remuneração por fora do que estava previsto no marco legal. No entanto, a partir do momento em que a prevalência do negociado sobre o legislado passou a ser vista como uma forma de rebaixar os direitos via negociação, ${ }^{14}$ houve uma reação contrária no interior da CUT. Mas, apesar de haver uma posição oficial da central contra a proposta,

${ }^{13}$ A pesquisa consistiu na realização de 94 entrevistas junto a dirigentes sindicais, entre setembro e novembro de 2018. Para maiores informações, cf. Galvão (2019).

${ }^{14}$ Pois a flexibilidade para cima, que agrega direitos, já existia (Uriarte, 2002). A novidade é a flexibilidade para baixo, que retira ou desregulamenta direitos. 
acordos de flexibilização da jornada e remuneração foram realizados por algumas entidades a ela filiadas (Galvão, 2007; Krein, 2007). Pouco a pouco, regulamentações legais foram derrogadas pela negociação, tais como a redução do horário de almoço, o banco de horas informal e de gaveta, a remuneração variável em mais de duas parcelas, a jornada de 12 por 36 etc. Por isso, considera-se que a reforma legaliza práticas já existentes (Galvão; Teixeira, 2018).

A maioria dos respondentes (72\%) da pesquisa da REMIR é contrária à prevalência do negociado por entender que essa medida, combinada com o fim da ultratividade dos acordos, enfraquece o sindicato e força negociações de rebaixamento de direitos, sobretudo em um contexto de crise econômica e de mudanças tecnológicas desfavoráveis ao trabalho e à ação coletiva. A prevalência do negociado sobre o legislado foi admitida por $23 \%$ dos respondentes do questionário, sendo que 14\% a admitem apenas em temas pontuais. Alguns consideram que a negociação pode suplantar a lei dependendo do tema, apontando que "deve haver um conjunto de direitos inegociáveis e que a possibilidade da negociação melhorar a lei está condicionada à força do sindicato" (Galvão, 2019, p 6).

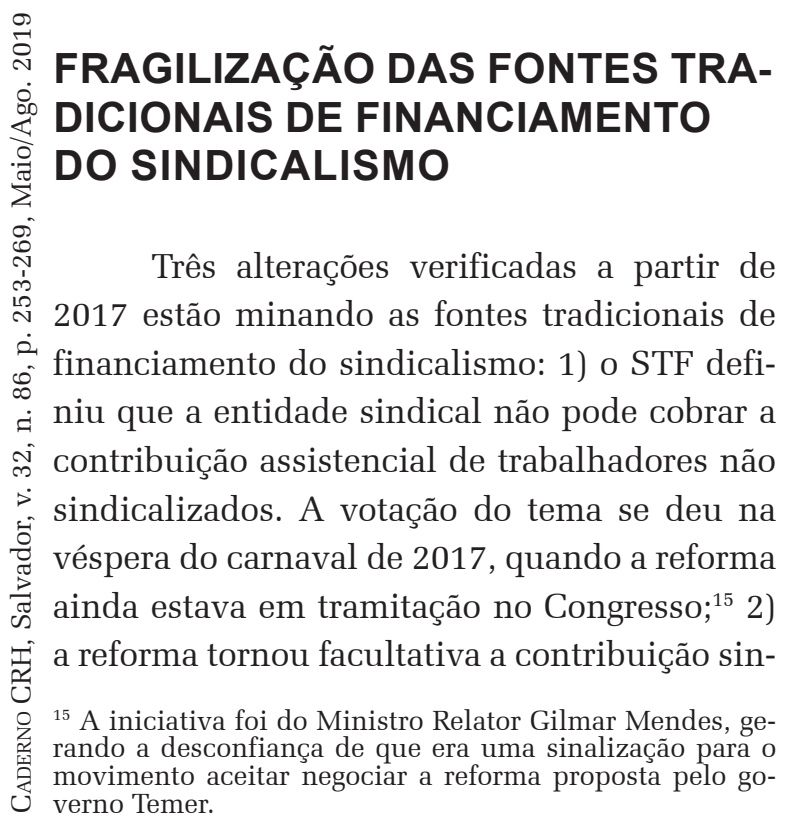

dical obrigatória e a constitucionalidade dessa medida foi referendada pelo STF em 2018; 3) a MP 873/19 editada pelo governo Bolsonaro na véspera do carnaval de 2019, obriga o trabalhador a autorizar, individualmente e por escrito, o desconto de qualquer contribuição ao seu respectivo sindicato. Também proíbe o desconto em folha de pagamento e sugere que a cobrança seja feita por boleto bancário. É uma alteração que afeta todas as formas de financiamento, inclusive, a mensalidade associativa.

A MP foi uma reação às formas de financiamento que os sindicatos estavam engendrando, tendo como referência a nota técnica elaborada pelo Ministério Público do Trabalho, para quem a cobrança do não sindicalizado beneficiado pela negociação coletiva não viola o princípio da liberdade sindical. Assim, o desconto dos não associados é permitido, desde que haja direito de oposição (Conalis, 2018). A MP está em vigor no momento em que o artigo é escrito, mas sua tramitação está parada na Câmara dos Deputados, o que indica a possibilidade de ela caducar decorridos 120 dias de sua publicação (01/03/19). No entanto, ela gerou uma série de polêmicas. Muitos juristas consideram que ela contraria a própria reforma ao suplantar a prevalência do negociado sobre o legislado. Sua função principal é enfraquecer as finanças sindicais, inclusive para imobilizar os sindicatos durante a tramitação da reforma da previdência, de modo consequente com o discurso governamental de acabar com qualquer ativismo.

$\mathrm{O}$ impacto da MP ainda não pode ser mensurado, mas as entidades sindicais já vinham sendo afetadas pela queda da arrecadação após a reforma. Dados do então Ministério do Trabalho mostram que a queda do valor do imposto sindical destinado às Centrais Sindicais foi próxima de 86\% em 2018. Segundo Luís Ribeiro, técnico da área de negociação coletiva do Dieese, a estimativa é de que os sindicatos tenham perdido até $80 \%$ na arrecadação. ${ }^{16}$

\footnotetext{
${ }^{16}$ Fonte: Subsecretaria de Orçamento e Administração do Ministério do Trabalho. Disponível em: https:/www.valor. com.br/brasil/5501555/arrecadacao-das-entidades-de-trabalhadores-com-imposto-sindical-diminui-80-em-2018
} 
Conforme a pesquisa da REMIR, o imposto sindical deixou de ser a principal fonte de sustentação dos sindicatos após a reforma. Apesar das ADINs impetradas no Supremo, as iniciativas sindicais não buscam manter o imposto sindical, mas introduzir outras formas de financiamento, especialmente por meio de cobranças vinculadas à negociação coletiva (Galvão, 2019, p.14). A taxa negocial tornou-se a estratégia mais utilizada mediante sua inclusão nas convenções e acordos, inclusive de PLR. A mensalidade também ganhou espaço, mas seu crescimento depende da ampliação do quadro de associados.

O Salariômetro (Fipe) ${ }^{17}$ aponta que "a contribuição para os sindicatos de trabalhadores foi o terceiro item mais frequente nas negociações", pois esteve presente em $49,8 \%$ dos acordos e convenções registradas no Sistema Mediador do Ministério do Trabalho em 2018. A taxa negocial ampliou sua presença nos instrumentos normativos de 5,5\% em 2017 para 38,2\% em 2018 (Galvão, 2019, p. 14-16).

Os sindicatos estão atuando em três frentes para se contrapor à MP: 1) pressão para que o Congresso Nacional a rejeite; 2) obtenção de liminares na Justiça, o que garantiu a vários sindicatos o desconto da mensalidade na folha de pagamento; ${ }^{18} 3$ ) discussão de formas alternativas de contribuição com desconto em conta, como foi a experiência do fundo de greve dos petroleiros em 1995 pois, mesmo em caso de vitória na Justiça, a empresa pode optar por depositar o valor em juízo e o recurso não vir para o sindicato. As categorias mais estruturadas do setor privado obtiveram o compromisso do setor patronal de que os descontos seguirão sendo realizados em folha de pagamento até a definição dos rumos da MP 873/19.

Além disso, algumas entidades estão

${ }^{17}$ Boletim Salariômetro, janeiro de 2019.

${ }^{18}$ Essa matéria ainda terá sua constitucionalidade apreciada pelo poder judiciário. De todo modo, as ações na justiça e os resultados favoráveis aos sindicatos mostram as contradições entre duas instâncias do Estado. Ver, entre outros: https://www.cut.org.br/noticias/sindicatos-podem-manter-cobranca-de-mensalidades-de-filiados-determina-justica-96c9 ampliando a prestação de serviços como forma de angariar sindicalizados e aumentar suas fontes de receita (Lucio, 2019).

\section{Reorganização sindical impulsionada pela reforma}

As dificuldades de financiamento, associadas às mudanças no mercado de trabalho, estão provocando uma reorganização sindical e da estrutura das entidades, na medida em que impõem um corte de gastos. Apesar da fragilidade de dados e da ausência de pesquisas mais sistemáticas, observações participantes e discussões com dirigentes e profissionais que atuam em entidades sindicais nos permitem indicar algumas tendências:

1. Esvaziamento das estruturas físicas e corte de pessoal nas centrais sindicais: a CUT reduziu a sua folha de pagamento em $40 \%$ e está se desfazendo de sua sede Central, e a CTB despediu a grande maioria de seus contratados. A UGT fechou a sede própria e se abrigou na sede do Sindicato dos Comerciários de São Paulo, e a NCST reduziu drasticamente suas atividades coletivas.

2. O fechamento de entidades sindicais, ${ }^{19}$ especialmente as dependentes do imposto sindical. Em muitos casos, fecha-se a sede, e a entidade continua formalmente aberta, mas sem estrutura e capacidade de organizar ação coletiva. Há situações também em que os sindicatos se unificam ou são incorporados por outros.

3. Reestruturação interna das entidades, com o fechamento de subsedes, secretarias, diminuição da infraestrutura, despedidas de empregados, redução das assessorias, mudanças para espaços mais baratos etc. Essa

${ }^{19}$ Lembrando que, no Brasil, há 11,2 mil sindicatos de trabalhadores, além de centrais, confederações e federações, e que boa parte dessas entidades é cartorial. E, portanto, plausível que esse número se reduza. Apenas para citar alguns exemplos: fechamento de cinco sindicatos de metalúrgicos no Estado de São Paulo; incorporação de sindicatos médicos de várias cidades vizinhas no sindicato de Campinas; fechamento da sede de 4 sindicatos do setor de comunicação em Curitiba. 
reorganização se deve, também, à queda expressiva das homologações. Em algumas entidades, a queda foi de mais de $90 \%$, impactando o número de funcionários e de ações trabalhistas, pois o sindicato não faz mais a conferência da rescisão contratual.

4. Propostas de criação de estruturas solidárias e compartilhadas em que várias entidades convivem no mesmo espaço físico. Mas, por enquanto, a reforma está provocando um movimento mais defensivo de adaptação à nova realidade financeira das entidades do que movimentos de construção de novas formas de organização criativas e solidárias. No plano do debate, novas ideias têm surgido: a combinação de uma ação mais tradicional no campo das relações de trabalho como uma forma de organização mais horizontalizada e capaz de abarcar o conjunto dos trabalhadores, inclusive os que não estão representados pela estrutura atual, tais como os trabalhadores de plataforma digital, os informais, os autônomos disfarçados e proletarizados, os terceirizados etc. Também há propostas de organização sindical por macrossetor, ${ }^{20}$ na perspectiva de organizar os trabalhadores por cadeia de produção global, estruturas solidárias reunindo vários sindicatos etc.

A postura defensiva fica evidente na F análise das greves realizadas no primeiro ano Ne vigência da reforma. Conforme já adianta$\stackrel{\infty}{\infty}$ mos na primeira seção deste artigo, foram realizadas 1453 greves em 2018, número inferior ao de 2017, mas superior aos anos anteriores a 2013. Houve uma mudança importante no perfil das paralisações. Elas foram promovidas por uma maioria de trabalhadores inseridos em ocupações mais vulneráveis, tanto em termos de condições de trabalho quanto em relação à remuneração. Os terceirizados dos setores público e privado foram os principais protagonistas das greves de 2018: vigilantes, recepcionistas, encarregados de limpeza, coleta de lixo e limpeza pública, rodoviários do

${ }^{20}$ Proposta da CUT desde 2012, em debate interno a partir de realização de seminários com dirigentes sindicais. transporte coletivo, enfermeiros e profissionais das Organizações Sociais de Saúde (OSS) (DIEESE, 2019).

No setor público, responsável por $54,4 \%$ das greves do período, destaca-se o protagonismo dos professores e profissionais de saúde das redes municipais. No setor privado, $74,8 \%$ das paralisações se concentraram no setor de serviços, seguido por $23,7 \%$ da indústria. As ocupações que mais deflagraram greves foram as do setor de transportes (35\%), trabalhadores de turismo e hospitalidade (26\%), saúde (20\%) e vigilantes (6\%). Sua pauta foi ainda mais defensiva do que no total das greves (90\% das reivindicações), com $64,9 \%$ exigindo pagamento de salário, de férias, do $13^{\circ}$ ou do vale salarial atrasados, e $25,7 \%$ reivindicando itens relacionados a alimentação, transporte e assistência médica. A maioria das greves se concentrou no âmbito da empresa ou unidade (88,9\%), não se estendendo para o conjunto da categoria. Observou-se um relativo sucesso dessas mobilizações, posto que $57,5 \%$ delas conquistaram integralmente suas reivindicações e 30\%, parcialmente.

Destacamos que, à exceção do setor de transportes e vigilantes, as categorias que puxaram as greves, tanto no setor público quanto no privado, são compostas majoritariamente por mulheres. São também categorias cujos setores não deixaram de gerar postos de trabalho, independentemente da crise.

\section{IMPACTOS NAS NEGOCIAÇÕES COLETIVAS}

Após o primeiro ano de vigência da reforma, o balanço das negociações é negativo entre os dirigentes, pois prevalece a visão de que a reforma está sendo implementada de forma unilateral pelos empregadores (Galvão, 2019). Uma pesquisa qualitativa realizada pelo Dieese, em parceria com a CUT (DIEESE/CUT, 2018), aponta que 59,5\% dos entrevistados avaliaram que as negociações ficaram piores, pois significaram perda de direitos e a possi- 
bilidade de incluir as demandas empresariais por flexibilização (Scherer, 2019 no prelo).

A reforma não estimulou a negociação coletiva. O número de acordos e convenções se reduziu em $22,7 \%$ e $25,3 \%$, respectivamente, entre os dez primeiros meses de 2018 e igual período de 2017 (Scherer, 2019 no prelo). A queda se explica tanto pela fragilização dos sindicatos quanto pela resistência deles em chancelar acordos prejudiciais aos trabalhadores e que não resolviam a sua situação financeira ${ }^{21}$. Mas, ao mesmo tempo em que os sindicatos buscam pela negociação coletiva, de modo a restringir o alcance das mudanças legais, a negociação vai consolidando os conteúdos introduzidos pela reforma.

As informações disponíveis no sistema Mediador apontam que, em 2018, estavam vigentes 3.568 convenções coletivas e 19 mil acordos coletivos. ${ }^{22}$ A partir desses dados, a Fipe (janeiro, 2019) indicou que, em 2018, aproximadamente $80,1 \%$ dos instrumentos normativos analisados obtiveram reajuste acima da inflação $(11,2 \%$ com reajuste igual à inflação e 8,7\%, abaixo, em um ano de baixa elevação dos preços). Os dados são mais favoráveis se comparados aos do ano de 2017. Os ganhos reais, em 2018, oscilaram entre $0,1 \%$ e 1,2\%. A recomposição das perdas salariais foi o principal tema da pauta das convenções e acordos coletivos. Em todos os instrumentos coletivos analisados, a reposição para os pisos salariais foi garantida. No entanto, na maior parte das categorias, se estabelece um teto para o reajuste e, acima dele, aplica-se um valor fixo. Essa estratégia tem se repetido para a maioria dos instrumentos negociados e evidencia as debilidades do movimento sindical em dialogar com os representados com salários

${ }^{21}$ Considerando que as diferenças entre 2017 e 2018 estão concentradas no primeiro semestre, avalia-se que a MP 808/17, que alterava os 17 artigos da lei 13.467/17, considerados mais nefastos por sindicalistas e parlamentares, pode ter provocado impasses nas negociações. A MP 808/17 não foi apreciada pelo congresso e caducou em abril de 2018 .

${ }^{22}$ A consulta foi realizada em 19/04/2019, e os acordos coletivos envolvem aditivos e acordos específicos. mais elevados. A reforma trabalhista estimula a prática da negociação direta para quem recebe acima de dois tetos previdenciários.

A reforma trabalhista rompe com padrões de negociação consolidados ao longo das últimas décadas, nos quais a norma mais favorável deveria prevalecer. As medidas definidas na Lei 13.467/17 estão centradas em novas modalidades de contratação, em alterações da jornada de trabalho, das formas de remuneração, das condições de trabalho, com o enfraquecimento dos sindicatos e da justiça do trabalho. Embora não haja um balanço consolidado do ano de 2018 sobre a evolução dessas cláusulas, já é possível aferir algumas tendências sobre sua efetividade a partir de alguns levantamentos realizados. Segundo o Dieese e a CUT (2018), os temas propostos pelo setor patronal são os seguintes: fim das homologações, acordo individual de banco de horas, compensação de jornada, jornada $12 \times 36$, parcelamento de férias, redução dos intervalos intrajornada, prevalência do negociado sobre o legislado, contrato intermitente, terceirização, fim da ultratividade e rescisão por comum acordo. Em levantamento também organizado pelo Dieese ( $1^{\circ}$ semestre de 2018), destacavam-se, além dos itens acima, a hora in itinere, demissão e contribuição assistencial e sindical.

Ressalta-se que a legislação já possibilitava a implementação de vários desses temas, por exemplo, o banco de horas, a redução dos intervalos intrajornada, a jornada $12 \times 36$ e a ultratividade, embora em alguns casos, como o da jornada $12 \times 36$, isso se destinasse a categorias específicas. As mulheres estão entre as mais afetadas por essas regras, pois como ainda cabe a elas a responsabilidade pelos cuidados familiares, elas terão mais dificuldade em se ajustar ao aumento do poder da empresa para manejar o tempo de trabalho de acordo com a dinâmica do negócio. Aliás, essas novas regras e lógicas de contratação diminuem a separação entre o tempo do trabalho e do não trabalho, dado que as mulheres e os homens serão exigidos em tempo integral. Examinamos, em seguida, cada um destes temas: 


\section{O acordo individual de banco de horas -} Embora a legislação date de 1998, sua principal motivação estava associada às crises econômicas e à recessão, e sua adoção era uma forma de evitar demissões em massa. Com a reforma trabalhista, ele passa ser permitido em qualquer situação e é considerado uma ferramenta essencial para o empregador flexibilizar as relações de trabalho e ajustar a jornada de trabalho, eliminando os tempos mortos. No banco de dados do Mediador, estão ativos $710^{23}$ instrumentos coletivos que fazem menção ao banco de horas. O tema é introduzido nas convenções coletivas pós-reforma sob diferentes perspectivas, por exemplo: os Químicos de São Paulo estabeleceram acordos de compensação anualizados, o que a Lei 13.467/17 permite desde que a compensação se dê no prazo máximo de seis meses; a Extração de Minério de Catalão previu a implantação do banco de horas, mas proibiu a possibilidade de acordo individual; a categoria de Alimentação de Cuiabá autorizou a implantação de banco de horas individual; os Mecânicos e trabalhadores em Material Elétrico da região Centro Oeste permitiram a definição de jornada de trabalho diferenciada por meio de acordo individual, sem a participação da entidade sindical; e a Autoescola de São Paulo indicou a proibição de acordos de banco de horas individual. A diversidade de redações expressa as tentativas de regular o tema por meio de instrumentos coletivos.

2. Redução dos intervalos intrajornada - Desde 2007, havia previsão legal para redução do intervalo do repouso mediante convenção ou acordo coletivo. A reforma retoma essa questão para eliminar possíveis controvérsias sobre o pagamento das horas devidas. A redução do intervalo de almoço para 30 minutos representa danos severos à saúde do trabalhador. Os empregos mais precários e que contam com pouca infraestrutura

${ }^{23}$ Consulta realizada no dia 19/04/2019. http://www3.mte. gov.br/sistemas/mediador/ConsultarInstColetivo no ambiente de trabalho, a exemplo de restaurantes e refeitórios, torna os 30 minutos insuficientes para esquentar marmita ou buscar comida nas proximidades do trabalho, estimulando uma alimentação precária e sem pausa para descanso. O tema está entre os mais frequentes, com 1.414 menções no Mediador. Nem todos os instrumentos autorizam a concessão de 30 minutos para o intervalo de descanso. No Transporte Coletivo de São Paulo, a convenção reitera o intervalo intrajornada de, no mínimo, 1 hora e, no máximo, 4, em virtude das condições especiais de trabalho; no acordo coletivo das Indústrias Químicas de Bauru, exige-se refeitório dentro do local de trabalho como condição para aplicar a redução do repouso intrajornada; no Sinergia da Bahia, a redução é opcional, cabendo ao empregado optar pela redução ou permanência do intervalo concedido; nos Enfermeiros do Pará, para qualquer trabalho contínuo que exceda as 6 horas, é obrigatória a concessão de um intervalo para repouso ou alimentação de, no mínimo, 1 hora.

3. Contrato intermitente - A maior parte dessa forma de contratação, que permite a prestação de serviços de forma descontínua, podendo alternar períodos em dia e hora, de modo a atender a demandas especificas, está concentrada no setor de comércio, hotéis, entidades recreativas e culturais, além da construção civil e transporte e logística. Presente em 148 instrumentos coletivos, as redações oscilam entre sua adoção e proibição, por ser incompatível com o princípio protetivo e ferir o artigo $7^{\circ} \mathrm{da} \mathrm{CF} / 88$. É o caso dos Condutores em Motocicletas de Campo Grande (MS); dos Empregados em Hotéis de Criciúma (SC), onde a contratação foi limitada à prestação de serviços em eventos; dos Trabalhadores e Instrutores em Autoescolas (SP), em que o trabalho intermitente não poderá ser utilizado nas atividades que não sejam sazonais, sob pena de nulidade; e dos Empregados em Refeições Coletivas do Es- 
tado de São Paulo, em que a contratação de trabalho na modalidade intermitente poderá ocorrer somente para as atividades eventuais, proibida a substituição por contratados a prazo indeterminado.

4. Homologação e rescisão por mútuo acordo - A possibilidade de que a homologação não seja realizada na entidade sindical e as demissões por acordo mútuo fortalecem a fraude, já que o trabalhador não terá a quem recorrer para verificar se está tendo acesso a todos os seus direitos. São as próprias empresas que passam a realizar as homologações, seja por meio de sua área de recursos humanos ou por empresas especializadas em gestão de desligamentos e processos de homologação. O fim das homologações no sindicato é uma das principais causas da queda acentuada dos processos na Justiça do Trabalho. A isso soma-se o receio do trabalhador de arcar com os custos processuais em caso de perda da ação. A cláusula da homologação foi retirada de parte significativa dos instrumentos: 1.206 tratavam desse assunto na data consultada, com queda de $40 \%$ em comparação a igual período do ano anterior. Nos instrumentos que mantiveram a cláusula, as redações assumiram novos conteúdos. As homologações deverão ser feitas, preferencialmente, no sindicato (Minérios e Derivados de Petróleo do RS); as empresas poderão homologar de forma opcional a rescisão contratual (Empregados de Empresas de Supermercado de Pernambuco); a homologação deverá ser realizada no sindicato desde que o trabalhador manifeste interesse por escrito ao seu empregador (Sindicato de Transportes de Carga do RS); as rescisões terão de ser obrigatoriamente submetidas à análise e posterior homologação pelo sindicato dos trabalhadores (Rurais de Sertanópolis, PR).

A reforma prevê a possibilidade de os contratos de trabalho serem extintos por acordo entre empregado e empregador, caso em que serão reduzidas as verbas rescisórias: aviso pré- vio indenizado pela metade e indenização sobre $\mathbf{8 0} \%$ do saldo do FGTS, sem ingresso no seguro-desemprego. A dispensa por acordo mútuo tem pouca frequência entre os instrumentos vigentes e, quando aparece, é para reafirmar que ela só poderá ocorrer mediante assistência do sindicato. No entanto, chama a atenção o seu crescimento: de novembro de 2017 a fevereiro de 2019 já tinham sido realizados 202.122 acordos.

5. Prevalência do negociado sobre o legislado - O Sindicato de Alimentação estabelece que toda e qualquer contratação e (ou) alteração contratual que tiver como base a Reforma Trabalhista será precedida de negociação com o ente coletivo representativo da categoria profissional, devido à supremacia do negociado sobre o legislado.

6. Contribuição assistencial e negocial - Embora ela fosse adotada pela maior parte dos sindicatos mais estruturados desde o início dos anos 2000, a grande maioria das pequenas entidades sobreviviam apenas do imposto sindical e, em alguns casos, da contribuição confederativa. Até a 19/04/2019, foram identificados 2.665 instrumentos vigentes ${ }^{24}$ que continham cláusulas sobre contribuição. Elas são amplas e também regulam a contribuição do empregador. Em alguns casos, é remetida para o acordo aditivo ou recomenda-se sua regulamentação por meio de acordos por empresa. A maior parte preserva o direito de oposição e, em alguns casos, o trabalhador não sócio que contribuir poderá usufruir da gratuidade do atendimento médico (caso da Construção Civil da Bahia); como as cláusulas também beneficiam o setor patronal, temos o exemplo do Sindicato dos Comerciantes de Içara (SC), que prevê a contribuição de R 20,00 por trabalhador, incluindo os terceirizados, contratados por jornada parcial ou intermitentes.

7. Ultratividade - Foram identificados 73 ins-

${ }^{24}$ Em número significativo, as cláusulas isentam o sindicato profissional das empresas de qualquer responsabilidade sobre os descontos realizados por força do artigo $8^{\circ}$, IV, da Constituição Federal. 
trumentos vigentes que tratam da ultratividade, e todos reafirmavam que, vencida sua vigência e enquanto não houver nova convenção ou acordo, deve prevalecer com plena eficácia jurídica a última norma coletiva firmada (ex.: Sindicato dos Trabalhadores em Vidros de SP).

8. Mulheres - A nova lei traz artigos que revogam ou alteram aspectos importantes da CLT que protegem as mulheres, tais como: (i) permissão para gestante ou lactante trabalhar em local insalubre; (ii) pausas para amamentação; (iii) salário igual para trabalho de igual valor. Esses aspectos foram remetidos para a livre negociação, abrindo espaço para pressões patronais sobre as trabalhadoras, que são coagidas a se submeter para preservar seu emprego. A defesa da permanência das mulheres em locais insalubres durante a gestação ou amamentação é baseada na manutenção do adicional de insalubridade, pois a trabalhadora que já recebe esse adicional seria prejudicada com a redução dos rendimentos, já que a lei estabelece que as mulheres grávidas ou que estejam amamentando serão temporariamente afastadas de locais insalubres de trabalho, mas veta a manutenção do salário integral com a inclusão dos adicionais de insalubridade. A mudança atribui o ônus e a responsabilidade da decisão de trabalhar em local insalubre integralmente às mulheres e despreza os impactos da medida para a saúde da trabalhadora e do feto, que poderá nascer com alguma malformação. Quanto ao horário de amamentação, a trabalhadora tem direito a dois intervalos de 30 minutos cada, durante a jornada, para amamentar crianças de até seis meses. Esse tempo, no entanto, torna muitas vezes inviável a amamentação durante a jornada, já que não há creches no local de trabalho ou devido às longas distâncias da residência até o trabalho. Por isso, há demandas de agrupar os intervalos ao final ou início da jornada. Lembramos que esse é um tema que poderá ser objeto de livre ne- gociação entre empregador e trabalhadora em um período em que a mulher se encontra fragilizada, especialmente quando termina sua a estabilidade provisória, o que traz novos desafios à negociação para as mulheres.

\section{CONSIDERAÇÕES FINAIS}

A indicação de que o sindicalismo precisa se reorganizar ou se reinventar depois da reforma trabalhista é recorrente tanto nas análises de pesquisadores quanto nas manifestações dos dirigentes sindicais. Esse debate já estava colocado antes da reforma, pois havia uma percepção de que o sindicalismo perdeu força na sociedade, e sua efetividade, na ação coletiva, já estava enfraquecida, especialmente em função das mudanças estruturais do mundo do trabalho.

O crescimento da precarização, que atinge mais fortemente as mulheres negras, promove uma reconfiguração da classe trabalhadora. As categorias que, historicamente, foram as bases mais dinâmicas e mobilizadas na ação coletiva ou estão perdendo postos de trabalho (indústria, o sistema bancário e o setor público) ou ampliando a ocupação, mas com aumento dos autônomos e da informalidade (educação e saúde). Ao mesmo tempo, as categorias com menor tradição sindical (atividades de serviços para empresas, comércio, alojamento e alimentação e informação e comunicação) e que concentram atividades precárias (subocupação, autônomos, sem registro em carteira e terceirizados) estão ganhando maior expressão numérica, em um contexto de hegemonia política e ideológica muito desfavorável à ação coletiva A perda de confiança da opinião pública nos sindicatos e a recente tendência mais defensiva das greves constituem uma expressão desse contexto adverso.

Assim, a reforma mexe com as estruturas sindicais, especialmente por (1) alterar as bases de representação; (2) minar as bases de financiamento das entidades; (3) redefinir o papel dos sindicatos, retirando atribuições e 
introduzindo novas, de modo a comprometê-lo com a "competitividade" da empresa e oferecer "segurança" para que as práticas patronais não sejam questionadas no judiciário.

Até o momento, as estratégias privilegiadas pelo movimento sindical têm buscado a adaptação aos efeitos da reforma, especialmente cortando custos e construindo iniciativas para garantir sua sobrevivência dentro dos parâmetros em que o sindicalismo estava organizado. Mas as inovações mais substantivas ainda estão mais no âmbito do debate do que da ação efetiva.

Quanto às negociações coletivas pós-reforma, observa-se uma queda dos instrumentos normativos assinados em 2018. O teor das negociações compreende um movimento contraditório, o que traduz a disputa em torno dos conteúdos da reforma. Por um lado, há estratégias e ações de resistência, que buscam atenuar os efeitos precarizantes e flexibilizadores dos elementos centrais da relação de emprego, procurando resguardar alguma regulação pública nas condições de contratação, uso e remuneração do trabalho. Por outro lado, vários temas que eram objeto de negociação desde os anos 1990 e que foram incorporados à reforma, especialmente os referentes à flexibilização da jornada, têm sido acordados nos instrumentos normativos, o que acaba por legitimar a reforma. Assim, as novas e velhas regulamentações vão redesenhando o mundo real do trabalho.

Em termos concretos, há um processo de fragilização das possibilidades de regulação pública do trabalho e das entidades sindicais, especialmente em sua capacidade de representar e negociar em termos mais centralizados e abrangentes. Com uma negociação coletiva cada vez mais descentralizada, como preservar direitos e proteções sociais de caráter universal? A estratégia sindical está, pois, desafiada a pensar em como preservar o caráter de classe e a capacidade de salvaguardar e ampliar direitos e proteção social.

Recebido para publicação em 21de abril de 2019 Aceito em 29 de maio de 2019

\section{REFERÊNCIAS}

ALCANTARA E SILVA, P. H. Os determinantes da filiação sindical dos empregados formais no Brasil (2003-2013). Dissertação (Mestrado) - Unicamp, 2017 (mimeo).

ALCANTARA E SILVA, P. H. de; KREIN, J. D. Comportamento da taxa de sindicalização nos governos do PT (2003-2013). In: XIV ENCONTRO NACIONAL DA ABET, Campinas, 2015.

ARAÚJO, Â. M.C.; FERREIRA, V. C. Sindicalismo e relações de gênero no contexto da reestruturacão produtiva. In: Rocha, M. I. B. (Org.) Trabalho e gênero: mudanças, permanências e desafios. São Paulo: Ed. 34, 2000. p. 309343.

ARAÚJO, Â. M. C.; VÉRAS DE OLIVEIRA, R. El sindicalismo em la era de lula: entre paradojas y nuevas perspectivas. Trabajo, México, v.5, n.2, p. 83-112, 2011

BOITO, A.; GALVÃO, A; MARCELINO, P. La nouvelle phase du syndicalismebrésilien. Cahiersdes Amériques Latines, n. 80, p.147-167, 2015.

BOITO JUNIOR, A.; MARCELINO, P. O sindicalismo deixou a crise para trás? Um novo ciclo de greves na década de 2000. Caderno CRH, Salvador, v. 23, n. 59, p. 323-338, 2010.

CAMPOS, C. V. Conflitos trabalhistas nas obras do PAC: o caso das Usinas Hidrelétricas de Jirau, Santo Antônio e Belo Monte. 2016. 220 p. Dissertação (Mestrado em Ciência Política) - Unicamp.

CARDOSO, A. Dimensões da crise do sindicalismo brasileiro. Cadernos CRH, Salvador, n. 75, 2015, p. 493510.

CASTRO, B. As armadilhas da flexibilidade. Trabalho e Gênero no Setor de Tecnologia da Informação. São Paulo: Annablume, 2016.

COLOMBI, A. P. A institucionalização do consenso: atuação da CUT e da FS nos governos do PT (2003-2014). 2018. Tese (Doutorado) - Universidade Estadual de Campinas, Instituto de Economia.

COLOMBI, A. P. F.; LEMOS, P. R.; KREIN, J.D. Entre negociação e mobilização: as estratégias da CUT e da FS frente à reforma trabalhista no Brasil. Revista da ABET, Paraná, v. 17, p. 179-198, 2018.

COORDENADORIA NACIONAL DE PROMOÇÃO DA LIBERDADE SINDICAL (CONALIS). Nota Técnica n. 02, 2018. Disponível em https://www.conjur.com.br/dl/mptpublica-nota-afronta-reforma.pdf. Acesso em: 15. 04. 2019.

DIEESE. Balanço das greves de 2018. Estudos e Pesquisa, Rio de Janeiro, n. 89, abr. 2019.

DIEESE/CUT. Acompanhamento das negociações coletivas pós reforma trabalhista. 2018.

DIEESE. Conjuntura das negociações coletivas. Impactos da reforma trabalhista no $1^{\circ}$ semestre de 2018. São Paulo, 2018. (Documento de circulação restrita).

GALVÃO, A. Um ano de vigência da reforma trabalhista: efeitos e perspectivas para os sindicatos. In: KREIN, J. D.; FILGUEIRAS,V.; VÉRAS, R.O. Reforma trabalhista no Brasil: promessas e realidade. Campinas/Brasilia: Curt Nimuendajú, 2019. (prelo)

GALVÃO, A. Neoliberalismo e reforma trabalhista no Brasil. Rio de Janeiro: Revan, 2007. v. 01. 342 p.

GALVÃO, A et al. (Org.) Dossiê Reforma Trabalhista. In: TEIXEIRA, M. et al. (Org.) Contribuição Crítica à Reforma Trabalhista. Campinas: Unicamp/Cesit, 2017. Disponível

em http://www.cesit.net.br/wp-content/uploads/2017/06/ Dossie-14set2017.pdf. Acesso em: 11.02.2019.

GALVÃO, A.; KREIN, J. D. Dilemas da representação e 
atuação sindical dos trabalhadores precários. In: RODRIGUES, I. J. (Org.) Trabalho e ação coletiva no Brasil: contradições, impasses, perspectivas (1978-2018). São Paulo: Annablume, 2019. p.203-233

GALVÃO, A.; MARCELINO, P. O sindicalismo brasileiro diante do golpe. In: COUTINHO, S. G. et al. (Org.) Reformas institucionais de austeridade, democracia e relações de trabalho. LTr: São Paulo, 2018. p. 85-96.

GALVÃO, A.; MARCELINO, P.; TRÓPIA, P. As bases sociais das novas centrais sindicais. Curitiba: Appris, 2015.

GALVÃO, A.; TEIXEIRA, M. Flexibilização na lei e na prática: o impacto da reforma trabalhista sobre o movimento sindical. In: KREIN, J. D.; GIMENEZ, D. M.; SANTOS, A. L. dos. Dimensões críticas da reforma trabalhista no Brasil. Campinas: Curt Nimuendajú, 2018. p. 155-181.

HIRATA, H.; HUMPHREY, J. Trabalhadores desempregados: trajetórias de operários e operárias industriais no Brasil. Revista Brasileira de Ciências Sociais, São Paulo, v. 4, n.11, out. 1989.

IBGE. Aspectos das relações de trabalho e sindicalização. IBGE: Rio de Janeiro, 2017.

KREIN, J. D. Tendencias recentes nas relações de emprego no Brasi : 1990-2005. 2007. 329 p. Tese (Doutorado) - Universidade Estadual de Campinas, Instituto de Economia, Campinas, SP. Disponível em http://www. repositorio.unicamp.br/handle/REPOSIP/285517. Acesso em: 10 ago. 2018.

KREIN, J. D.; DIAS, H. Os caminhos do sindicalismo nos anos 2000. Revista Ciências do Trabalho, São Paulo, n. 8, p. 1-17, 2017.

KREIN, J. D. et al. Dimensões críticas da reforma trabalhista no Brasil. Campinas: Curt Nimuendajú, 2018.

KREIN, J. D.; VÉRAS, R. O. As condições de trabalho pós reforma. In. KREIN, J. D, FILGUEIRẢS,V.; VÉRAS, R. O. Reforma Trabalhista no Brasil: promessas e realidade. Campinas/Brasilia: Curt Nimuendajú, 2019. (prelo)
LINHARES, R. As greves de 2011 a 2013. Revista Ciências do Trabalho, São Paulo, n. 5, p. 97-112, 2015.

LUCIO, C. G. Novas regras trabalhistas em vigor: desafios do sindicalismo. In. Confetam. Disponível em http://www. confetam.org.br/noticias/novas-regras-trabalhistas-emvigor-desafios-do-sindicalismo-5db4/. Acesso em: 15. 04. 2019.

MARCELINO, P. Sindicalismo e neodesenvolvimentismo. Analisando as greves entre 2003 e 2013 no Brasil. Tempo Social, São Paulo, v. 29, n. 3, p. 201-227, 2017.

MATTOS, M. B. As lutas da classe trabalhadora no Brasil dos "mega-eventos". Observatório Social da América Latina, Buenos Aires, n. 36, p. 215 -226, 2014.

PERSEU ABRAMO. Boletim de Análise de Conjuntura n. 4, 2019.

RODRIGUES, I. J.; RAMALHO, J. R. Novas configurações do sindicalismo no Brasil? Uma análise a partir do perfil dos trabalhadores sindicalizados. Contemporânea Revista de Sociologia da UFSCar, São Carlos, v. 4, n. 2, p. 381-403, 2014.

SCHERER, C. Diálogo e proteção social - a negociação coletiva após um ano de Reforma Trabalhista In: KREIN, J. D.; FILGUEIRAS, V.; VÉRAS, R. O. Reforma Trabalhista no Brasil: promessas e realidade. Campinas: Curt Nimuendajú, 2019. (prelo).

TEIXEIRA, M. O. Um olhar da economia feminista para as mulheres: os avanços e as permanências das mulheres no mundo do trabalho entre 2004 e 2013. 2017. Tese (Doutorado) - Programa de Pós-Graduação em Desenvolvimento Econômico, Instituto de Economia, Universidade Estadual de Campinas.

URIARTE, A.E. A flexibilidade. São Paulo: Editora LTr, 2002 .

VÈRAS DE OLIVEIRA, R. Brasil em obras, peões em luta, sindicatos surpreendidos. Revista Crítica de Ciências Sociais, Coimbra, n. 103, p. 111-136, 2014. 


\section{LABOR REFORM: precarious work and the challenges for unions}

\author{
Andréia Galvão \\ Bárbara Castro \\ José Dari Krein \\ Marilane Oliveira Teixeira
}

\section{RÉFORME DU TRAVAIL: le travail précaire et les défis du syndicalisme}

\author{
Andréia Galvão \\ Bárbara Castro \\ José Dari Krein \\ Marilane Oliveira Teixeira
}

The paper proposes to identify the initial impacts of the labor reform on trade unionism, in a context that is unfavorable to workers and to collective action, resulting from the transformations in the reconfiguration of the working classes, with the growth of precariousness and crisis of the labor market. The analysis focuses on the impacts of this reconfiguration of the working classes and the fragmentation of trade unions, as well as the impacts of the labor reform on union strategies and actions and on collective negotiation. The methodology combined quantitative labor market research with documents (collectives work contracts, commercial and trade union press materials) and participant observation. The results show that the trade unions are searching to adapt to the new context with some substantive innovations in action and organization. The latest negotiations have been, at the same time, spaces of resistance and legitimization of the content of the reform.
Larticle propose d'identifier les impacts initiaux de la réforme du travail sur le syndicalisme, dans un contexte défavorable aux travailleurs et à l'action collective, en raison du développement de la précarité et de l'informalité dans le marché du travail. L'analyse porte sur la reconfiguration de la classe ouvrière et de la fragmentation syndicale, aussi bien que sur les impacts de la réforme sur les stratégies et actions des syndicats et sur la négociation collective. La méthodologie combine une étude quantitative du marché du travail avec des documents (contrats de travail collectives, matériel de presse commerciale et syndicale) et de l'observation participante. Les résultats montrent que les syndicats essayent de s'adapter au nouveau contexte, avec de petites innovations substantielles dans l'action et l'organisation, et que les négociations sont autant des espaces de résistance comme de légitimation du contenu de la réforme.

KEywords: Trade unionism. Labor reform. Mots-clés: Syndicalisme. Réforme du travail. Precariousness. And collective bargaining.

Andréia Galvão - Professora de Ciência Política da Unicamp. Editora da revista Crítica Marxista. Pesquisa relações de trabalho, sindicalismo e movimentos sociais no Brasil. Publicações recentes: Neoliberalismo e reforma trabalhista no Brasil (Revan-Fapesp, 2007); Política e classes sociais no Brasil dos anos 2000 (Alameda, 2012); As bases sociais das novas centrais sindicais brasileiras (Appris, 2015).

Bárbara Castro - Doutora em Ciências Sociais pela Universidade Estadual de Campinas. Professora do Departamento de Sociologia da Universidade Estadual de Campinas. Coordenadora do Programa de Pós-Graduação em Sociologia da Universidade Estadual de Campinas. Pesquisadora-associada ao Núcleo de Estudos de Gênero - PAGU, desenvolvendo pesquisas na área de trabalho, gênero e usos do tempo. Publicações recentes: Quando gênero revela classe: mulheres e flexibilidade no setor de Tecnologia da Informação. In: Ricardo Antunes. (Org.). Riqueza e miséria do trabalho no Brasil IV. 1ed.São Paulo: Boitempo, 2019; Feminizando chefias? Uma análise da dinâmica da divisão sexual do trabalho no setor de TI. Revista da ABET, v. 17, p. 16-27, 2018.; As armadilhas da flexibilidade: trabalho e gênero no setor de tecnologia da informação. 1. ed. São Paulo: Annablume, 2016; Trabalho perpétuo: o viés de gênero e o ideal de juventude no capitalismo flexível. Lua Nova (Impresso), v. 99, p. 169-199, 2016.

José Dari Krein - Professor do Instituto de Economia e pesquisador do CESIT (Centro de Estudos Sindicais e Economia do Trabalho). Presidente da ABET (2007-2009). Pesquisa relações e mercado de trabalho, sindicalismo e negociações coletivas. Coordenação da REMIR (Rede de Estudo e Monitoramento Interdisciplinar da Reforma Trabalhistas, em 2019). Publicações recentes: The CUT'S Experience during the Workers' Party Governments in Brazil (2003-2016). Global Labour Journal, v. 9, p. 199-214, 2018; Flexibilização das relações de trabalho: insegurança para os trabalhadores. Revista do Tribunal Regional do Trabalho da 15. Região, v. 1, p. 41-66, 2018; Aspectos para discutir o significado da contrarreforma trabalhista e suas consequências. Intervozes, v. 3, p. 112-116, 2018.

Marilane Oliveira Teixeira - Doutora em desenvolvimento econômico e social pelo IE da UNICAMP. Pesquisadora na área das relações de trabalho, gênero e sindicalismo. Integra núcleo de reflexões sobre economia feminista na UNICAMP e o núcleo de pesquisa sobre mercado de trabalho, relações de trabalho e sindicalismo no CESIT. 
